\title{
Spirometry in chronic obstructive pulmonary disease in Norwegian general practice
}

\author{
Mette C. Tollånes ${ }^{1 *}\left(\mathbb{D}\right.$, Geir E. Sjaastad ${ }^{2}$, Bernt B. Aarli ${ }^{3,4}$ and Sverre Sandberg ${ }^{1,5,6}$
}

\begin{abstract}
Background: General practitioners (GPS) in Norway increasingly use spirometry diagnostically as well as in follow up of patients with respiratory complaints, but little is known about their skills and knowledge in this area. The aim of the present study was to investigate how GPs interpret a case history and spirometry recordings of a patient with chronic obstructive pulmonary disease (COPD), and their knowledge about their own spirometer.
\end{abstract}

Methods: A web-based survey, consisting of a case history and spirometry recordings of a patient with COPD, was distributed to the 4700 members of the Norwegian GP Association. In addition to background information about themselves and their spirometer, topics included whether they requested, and how they interpreted, a spirometry reversibility-test, identification of the of most likely diagnosis, and recognition of the spirometry parameters used to diagnose COPD and grade airway obstruction. Immediate feedback was provided for educational purposes.

Results: Six hundred thirty GPs responded. Twenty six percent would not request a reversibility test, but $81 \%$ identified COPD as the most likely diagnosis. Less than $50 \%$ correctly identified the spirometry parameters used for diagnosis of COPD and grading the airway obstruction. One in five (21\%) did not know which spirometer was used in their own practice, and 49 and $61 \%$ did not know which reference values were used for adults and children, respectively. Participants evaluated the survey as useful (average 74 points on a 0-100 scale) and would like more case-based surveys concerning use of spirometry in the future (average 91 points).

Conclusion: In this cohort of self-selected GPs, probably more interested in respiratory medicine than the average $\mathrm{GP}$, we identified several problem areas and gaps in knowledge regarding the use of spirometry.

Keywords: Spirometry, General practice, Chronic obstructive pulmonary disease, Web-based survey

\section{Background}

General practitioners (GPs) in Norway increasingly use spirometry diagnostically as well as a tool to evaluate lung function during follow up of patients with respiratory complaints. In 2018, approximately $97 \%$ of practicing GPs were reimbursed for performing spirometry

\footnotetext{
* Correspondence: mette.tollanes@noklus.no

${ }^{1}$ Norwegian Organization for Quality Improvement of Laboratory Examinations, Haraldsplass Deaconess Hospital, Bergen, Norway Full list of author information is available at the end of the article
}

tests, on average 30 times, with a total cost of approximately 41.9 million Norwegian kroner [1].

Previous studies have found that GPs do not always know when to request a spirometry, nor how to interpret it. In a study from seven Norwegian GP offices during 2009/2010, patients with a record of asthma or chronic obstructive pulmonary disease (COPD) were invited for clinical examination and spirometry to validate their diagnoses [2]. Of the 128 patients registered with COPD, only $74 \%$ fulfilled the spirometric criteria. Among the patients clinically diagnosed with asthma, $17 \%$ were re-diagnosed

(c) The Author(s). 2020 Open Access This article is licensed under a Creative Commons Attribution 4.0 International License, which permits use, sharing, adaptation, distribution and reproduction in any medium or format, as long as you give appropriate credit to the original author(s) and the source, provide a link to the Creative Commons licence, and indicate if changes were made. The images or other third party material in this article are included in the article's Creative Commons licence, unless indicated otherwise in a credit line to the material. If material is not included in the article's Creative Commons licence and your intended use is not permitted by statutory regulation or exceeds the permitted use, you will need to obtain permission directly from the copyright holder. To view a copy of this licence, visit http://creativecommons.org/licenses/by/4.0/ The Creative Commons Public Domain Dedication waiver (http://creativecommons.org/publicdomain/zero/1.0/) applies to the data made available in this article, unless otherwise stated in a credit line to the data. 
with COPD. Similar results were found in a UK study from 2017, where spirometries performed in primary care were re-assessed by pulmonologists [3]. While $96 \%$ of spirometry recordings were of adequate technical quality, only $73 \%$ of spirometries from patients with a clinical diagnosis of COPD were consistent with obstruction. A recent case-based survey among 250 Swedish GPs concluded that although the GPs indicated they would often request a spirometry when appropriate, only $23 \%$ could adequately interpret the spirometric recordings [4].

The Norwegian Organization for Quality Improvement of Laboratory Examinations (Noklus) has provided quality systems for point-of-care laboratory testing in primary care since 1992 [5], including courses, site visits, laboratory instrument evaluations, and external quality assurance (EQA) schemes. The main aim of the present study, conducted in collaboration with the Norwegian GP Association and the Norwegian Respiratory Society, was to investigate how GPs in Norway interpret a case history and spirometry recordings of a patient with COPD. A secondary aim was to investigate the GPs' knowledge about their own spirometer.

\section{Methods}

In 2019, we distributed a web-based multiple-choice survey (Additional file 1) to the 4712 practicing GPs registered as members of the Norwegian GP Association, with the following case history:

A previously healthy man in the age group 50-59 years presents with complaints of progressive breathlessness on physical exertion over the past year. He has never had atopic symptoms, asthma or allergy, and there is no family history of lung-or upper airway disorders. He started smoking in his late teens but quit four years ago. You request a spirometry. Do you include a reversibility test or not?

We asked which type of spirometer participants used (see Additional file 1 for details), and pictures of spirometry recordings were adapted accordingly to ensure recognizability. Participants were asked for the most likely diagnosis, and which spirometric parameters they used to diagnose the disease and grade airway obstruction. After choosing an answer, participants were immediately presented with the correct/ preferred answer, as well as updated references for further reading. We also asked about general knowledge of their spirometer (need for calibration, reference values used), and some background information (geographic region, number of patients served, number of spirometries usually requested during a regular work week). Finally, we asked how useful they found the survey and if they would like more surveys concerning spirometry in the future.

The case history and spirometry recordings were of a patient with COPD, which was the correct most likely diagnosis. In line with the Norwegian Directorate of Health's guidelines on management of COPD [6], we used the Global Initiative for Chronic Obstructive Lung Disease (GOLD) criteria of postbronchodilator $F E V_{1} /$ $F V C$ ratio $<0.70$ for diagnosis of COPD and $F E V_{1}$ in \% of predicted to grade the airway obstruction $(\geq 80 \%$ : GOLD 1 - mild airway obstruction, 50-79\%: GOLD 2 moderate airway obstruction, 30-49\%: GOLD 3 - severe airway obstruction, and $<30 \%$ : GOLD 4 - very severe airway obstruction) [7].

The survey was open exclusively to invited GPs for a four-week period, and only responses collected during this period were analyzed for the present study. Afterwards, a link to the survey was posted on Noklus' website [8]. Descriptive statistics were performed using $\mathrm{R}$ version 3.6.1 [9]. Chi-square tests were used to investigate differences between groups, and $p$-values $<0.05$ were considered statistically significant.

\section{Results}

A total of 749 responses were collected during the fourweek period of data collection, partially or completely. Participants spent on average 5-6 min on the survey. Forty-two respondents indicated they were not currently practicing GPs. Of the remaining, 47 responses were excluded because respondents had not answered the question of the most likely diagnosis, and 30 because they were not first-time responses (Fig. 1).

Four hundred sixty-seven participants (74\%) indicated they would request a reversibility test (Table 1), which was considered the correct answer, since this was the only option providing a post bronchodilator spirometry which is required to diagnose COPD [6]. When presented with pre- and postbronchodilator spirometry recordings, 582 (92\%) correctly recognized that there was no significant reversibility (Table 1 ). Five hundred twelve participants (81\%) correctly identified COPD as the most likely diagnosis. Only 287 (46\%) correctly indicated they used only $F E V_{1} / F V C$ ratio for diagnosing COPD, and 269 (43\%) correctly indicated they used only $F E V_{1}$ in \% of predicted to grade the airway obstruction.

Welch-Allyn (Hill-rom Services Inc) and Spirare (Diagnostica AS) were by far the most commonly used spirometers, but 133 participants (21\%) did not know which type of spirometer was used in their practice (these participants were provided with Spirare printouts in the survey). The majority of participants indicated they would request between one and four spirometries per week, while 70 (11\%) said they would request no spirometries during a regular working week (Table 2). GPs 


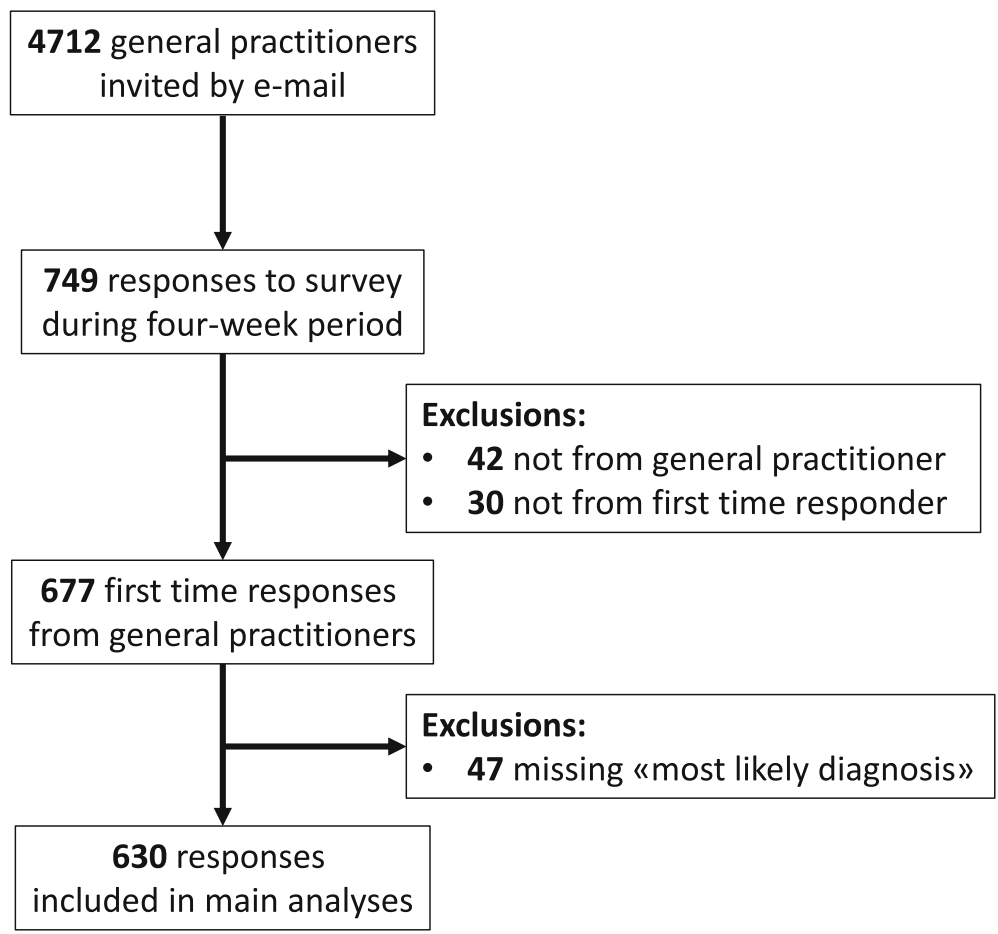

Fig. 1 Flow chart of participants

who requested more spirometries per week or served more patients, were more likely to recognize COPD as the correct diagnosis ( $p$-values for trend $<0.001$ and 0.02 , respectively), but these factors were not associated with other outcomes. Type of spirometer used was generally not associated with performance in the survey (Table 2).

Two hundred sixty-nine participants (43\%) indicated they did not know if, or how often, their spirometer should be calibrated. Only 85 participants (13\%) indicated that they used the recommended Global Lung Initiative (GLI) reference values for adults, and 70 participants $(11 \%)$ that they used the recommended GLI reference values for children. 308 (49\%) and 386 participants (61\%) did not know which reference values were reported by their spirometer for adults and children, respectively.

Participants evaluated the survey as useful (average 74 points on a 0-100 scale, standard deviation (SD) 24 points) and would like more case-based surveys concerning use of spirometry in the future (average 91 points, SD 17 points).

\section{Discussion}

We investigated how GPs in Norway would interpret a case history and spirometry recordings of a patient with COPD, as well as their knowledge about their own spirometer. Most GPs were able to recognize a non- significant reversibility test, and $81 \%$ correctly identified COPD as the most likely diagnosis. Less than $50 \%$ of GPs, however, were able to correctly identify the spirometric parameters used to diagnose COPD and to grade the airway obstruction. Many were unaware of which type of spirometer and reference values were in use in their practice.

\section{Strengths and limitations}

An important strength of our study is the broad recruitment; the invitation was distributed through the membership records of the Norwegian GP Association. While probably not $100 \%$ complete, this is the most updated source of e-mail addresses for GPs in Norway. Still, the low participation rate is a weakness of our study, limiting our ability to draw general conclusions about spirometry in general practice. Since there was self-selection of GPs into the survey, there is reason to believe that participating GPs, on average, were more interested in respiratory medicine than non-participants. Consequently, when we find knowledge gaps and problem areas, we probably underestimate rather than overestimate the challenges in this area for the GP population at large. Also, the design of a cross-sectional survey means we cannot draw inferences about cause and effect. Finally, as respondents were anonymous, a follow-up study to asses learning effects of the survey cannot be performed, leaving us only to speculate whether short 
Table 1 Distribution of responses to survey

\begin{tabular}{|c|c|}
\hline Question & $\mathrm{N}$ responses $(\%)$ \\
\hline \multicolumn{2}{|l|}{ Do you request a reversibility test? } \\
\hline Yes & $467(74.1)$ \\
\hline No & $160(25.4)$ \\
\hline Missing & $3(0.5)$ \\
\hline \multicolumn{2}{|l|}{ Is there significant reversibility? } \\
\hline Yes & $25(4.0)$ \\
\hline No & $582(92.4)$ \\
\hline Don't know & $17(2.7)$ \\
\hline Missing & $6(1.0)$ \\
\hline \multicolumn{2}{|l|}{ What is the most likely diagnosis? } \\
\hline No pulmonary disorder/healthy & $18(2.9)$ \\
\hline Asthma & $9(1.4)$ \\
\hline Restrictive pulmonary disorder & $26(8.9)$ \\
\hline COPD & $512(81.3)$ \\
\hline Other & $10(1.6)$ \\
\hline Don't know & $25(4.0)$ \\
\hline \multicolumn{2}{|c|}{ Which parameter(s) did you use to diagnose COPD? } \\
\hline FVC & $6(1.0)$ \\
\hline FVC in percent of predicted & $11(1.8)$ \\
\hline FEV1 & $16(2.5)$ \\
\hline FEV1 in percent of predicted & $32(5.1)$ \\
\hline FEV1/FVC ratio & $287(45.6)$ \\
\hline FEV1/FVC ratio in percent of predicted & $48(7.6)$ \\
\hline More than one option chosen & $219(34.8)$ \\
\hline Missing & $11(1.8)$ \\
\hline \multicolumn{2}{|c|}{ Which parameter(s) did you use to grade airway obstruction? } \\
\hline FVC & $7(1.1)$ \\
\hline FVC in percent of predicted & $19(3.0)$ \\
\hline FEV1 & $113(17.9)$ \\
\hline FEV1 in percent of predicted & $269(42.7)$ \\
\hline FEV1/FVC ratio & $75(11.9)$ \\
\hline FEV1/FVC ratio in percent of predicted & $42(6.7)$ \\
\hline More than one option chosen & $59(9.4)$ \\
\hline Missing & $46(7.3)$ \\
\hline
\end{tabular}

surveys can be useful tools in continuous medical education.

Current Norwegian COPD guidelines [6] are in line with the GOLD recommendations, using post-bronchodilator fixed ratio of $F E V_{1} / F V C<0.7$ to spirometrically define airway obstruction [7]. The fixed ratio is a choice of diagnostic simplicity and may lead to misclassifications, particularly overdiagnosis of COPD in the elderly, as the $F E V_{1} / F V C$ ratio decreases with age [10]. A more accurate definition of airway obstruction is $F E V_{1} / F V C$ ratio below the lower 5 th percentile observed in a healthy, relevant population. Modern spirometers report this lower limit of normal (LLN) as z-scores, as does a frequently used Norwegian web-based decision support tool in COPD (www. kolskalkulator.no). We did not include this parameter in our survey, which may be added in future surveys.

\section{Comparison to previous findings}

Prevalence of COPD varies greatly between studies, probably due to differences between populations and diagnostic criteria used [11]. Both over- and underdiagnosis of COPD likely happen in parallel. Overdiagnosis of COPD is largely attributed to diagnosing without performing the required spirometry [11]. In a multi-center study from 20 countries, more than $60 \%$ of patients who reported that they had been diagnosed with COPD, did not have airflow obstruction on spirometry [12]. In a Norwegian study, $26 \%$ of patients with a medical record of COPD, did not fulfill the spirometric criteria [2]. Similar findings were reported in a UK study [3]. Underdiagnosing on the other hand, is mainly attributed to insufficient use of spirometry and missed diagnostic opportunities [11]. A retrospective UK study of almost 40,000 patients with COPD, based on electronic medical records from primary care, found that opportunities for diagnosis were missed in $85 \%$ of the patients in the 5 years immediately preceding the diagnosis [13]. A Danish study found that opportunistic screening of 6700 at-risk patients in primary care identified that almost $18 \%$ had COPD [14]. In our survey, a premise was that everyone requested a spirometry for our at-risk patient. Therefore, we could not estimate potential under- or over-diagnosis directly. However, our case history and spirometry recordings were designed to illustrate a textbook example of a COPD patient. In short, our results showed that the knowledge on use and interpretation of spirometry in Norwegian general practice was suboptimal.

In Sweden, 250 GPs participated in a questionnairebased study to investigate knowledge about diagnosis and treatment of COPD in general practice [4]. Spirometry was frequently used, but only $23 \%$ of GPs correctly interpreted the spirometry on the basis of postbronchodilator parameters [4]. Our results were similar; less than $50 \%$ of GPs correctly identified spirometric parameters used to 1) diagnose COPD, and to 2) grade airway obstruction. Only 143 of 630 (23\%) correctly identified both parameters.

\section{Interpretation and implications}

In our survey, we observed that requesting more spirometries during a regular week, and serving more patients, were factors associated with a higher chance of recognizing the correct diagnosis. This could be an indication that requesting more spirometries improves interpretation 
Table 2 Performance in survey (number (and fraction) of correct answers) by type of spirometer used, number of spirometries requested during a regular week, and number of patients served by the GP

\begin{tabular}{|c|c|c|c|c|c|}
\hline & $\begin{array}{l}\text { Requested } \\
\text { reversibility } \\
\text { test } \\
\end{array}$ & $\begin{array}{l}\text { Recognized non-sign. } \\
\text { Reversibility test }\end{array}$ & $\begin{array}{l}\text { Suggested COPD as } \\
\text { likely diagnosis }\end{array}$ & $\begin{array}{l}\text { Identified } \\
\text { parameter } F E V_{1} / F V C \\
\text { ratio }\end{array}$ & $\begin{array}{l}\text { Identified parameter } \\
\text { FEV } 1_{1} \text { in } \% \text { of predicted }\end{array}$ \\
\hline \multicolumn{6}{|l|}{ Type of spirometer used } \\
\hline Welch-Allyn ( $n=311)$ & $231(0.75)$ & $288(0.93)$ & $252(0.81)$ & $167(0.54)$ & $124(0.40)$ \\
\hline Spirare $(n=169)$ & $129(0.76)$ & $159(0.94)$ & $143(0.85)$ & $69(0.41)$ & $80(0.47)$ \\
\hline $\begin{array}{l}\text { Other/Don't know }(n= \\
\text { 150) }\end{array}$ & $107(0.72)$ & $135(0.90)$ & $117(0.78)$ & $51(0.34)$ & $65(0.43)$ \\
\hline $\begin{array}{l}p \text {-value for difference, all } \\
\text { groups }\end{array}$ & 0.65 & 0.38 & 0.32 & $<0.001$ & 0.28 \\
\hline $\begin{array}{l}\text { p-value for difference, } \\
\text { excluding "Other/Don't } \\
\text { know" }\end{array}$ & 0.70 & 0.54 & 0.33 & 0.01 & 0.11 \\
\hline \multicolumn{6}{|c|}{ Number of spirometries requested per week } \\
\hline None $(n=70)$ & $53(0.76)$ & $64(0.91)$ & $48(0.69)$ & $32(0.46)$ & $29(0.41)$ \\
\hline $1-4(n=403)$ & $308(0.77)$ & $383(0.95)$ & $358(0.89)$ & $193(0.48)$ & $203(0.50)$ \\
\hline 5 or more $(n=30)$ & $27(0.90)$ & $29(0.97)$ & $29(0.97)$ & $19(0.63)$ & $15(0.50)$ \\
\hline Missing $(n=127)$ & $79(0.63)$ & $106(0.84)$ & $77(0.61)$ & $43(0.34)$ & $22(0.17)$ \\
\hline $\begin{array}{l}p \text {-value for difference, all } \\
\text { groups }\end{array}$ & $<0.01$ & $<0.001$ & $<0.001$ & 0.01 & $<0.001$ \\
\hline $\begin{array}{l}p \text {-value for trend, excluding } \\
\text { "Missing" }\end{array}$ & 0.23 & 0.20 & $<0.001$ & 0.20 & 0.25 \\
\hline \multicolumn{6}{|c|}{ Number of patients served by GP } \\
\hline$<1000(n=181)$ & $142(0.79)$ & $167(0.92)$ & $148(0.82)$ & $88(0.49)$ & $93(0.51)$ \\
\hline $1000-1499(n=294)$ & $221(0.75)$ & $284(0.97)$ & $259(0.89)$ & $142(0.48)$ & $147(0.50)$ \\
\hline$\geq 1500(n=33)$ & $27(0.82)$ & $33(1.00)$ & $31(0.94)$ & $17(0.52)$ & $11(0.33)$ \\
\hline Missing $(n=122)$ & $77(0.64)$ & $98(0.80)$ & $74(0.61)$ & $40(0.33)$ & $18(0.15)$ \\
\hline $\begin{array}{l}p \text {-value for difference, all } \\
\text { groups }\end{array}$ & 0.02 & $<0.001$ & $<0.001$ & 0.02 & $<0.001$ \\
\hline $\begin{array}{l}p \text {-value for trend, excluding } \\
\text { "Missing" }\end{array}$ & 0.88 & 0.75 & 0.02 & 0.67 & 0.12 \\
\hline
\end{tabular}

skills or that GPs already competent in the use of spirometry request more spirometries. We can similarly speculate that serving more patients is associated with more experience and practice in this field, but we are not able to explore these matters further. There were no associations between number of spirometries requested or patients served and the other outcomes we examined, which, in addition to the self-selection of GPs into the study, means these observations must be interpreted with caution.

Efficient continuing medical educations on complex health issues can be challenging in general practice. As a follow up to the Swedish study [4], primary care centers were later randomized to compare the impacts of two types of continuing medical education designed to improve GPs knowledge of COPD, either traditional lectures or a case-based method, both consisting of two 2-h sessions within 3 months. Compared with a reference group, both interventions gave only marginal improvements in the GPs knowledge measured after 12 months [15]. Others have found at least short-term positive effects of educational interventions when used in combination (short lectures, case discussions, spirometry workshops, inhalation demonstrations) [16, 17]. Our survey is now available online as a "mini-course" of spirometry in COPD, an easily accessible resource for GPs in need of a quick repetition. The participants evaluated our survey as useful and said they would like more casebased surveys concerning the use of spirometry in the future. Thus, to offer an online repository of "minicourses" in spirometry is a goal. Since respondents undertook the survey anonymously, a rigorous and longterm investigation of any learning effects of such a survey is not possible at present.

Spirometry recordings contain a large number of parameters that are not necessary for correct interpretation in general practice. Our results confirm that there is 
substantial confusion among GPs on which parameters to use. Therefore, more user-friendly spirometry software which displays and highlights important parameters and suppresses parameters of less importance, could perhaps also improve spirometry interpretation in general practice.

\section{Conclusion}

We conducted a web-based survey, now available online as a "mini-course", and identified knowledge gaps and problem areas in requesting and interpreting spirometry in Norwegian general practice. Whether such short online courses may be a useful resource to help improve lung disorder management in general practice, may be a future topic of investigation.

\section{Supplementary Information}

The online version contains supplementary material available at https://doi. org/10.1186/s12875-020-01310-x.

Additional file 1. Survey translated into English.

\section{Abbreviations}

COPD: Chronic Obstructive Pulmonary Disease; FEV 1 : Forced Expiratory Volume in one second; FVC: Forced Vital Capacity; GOLD: Global Initiative for Chronic Obstructive Lung Disease; GP: General practitioner

\section{Acknowledgements}

We are grateful to all GPs that completed the survey.

\section{Authors' contributions}

MCT contributed to conception and design of the study, collected and analyzed the data, and wrote the first draft of the paper. GES contributed to conception and design of the study, interpretation of results and revision of the manuscript. BBA contributed to conception and design of the study, interpretation of results and substantively revised the manuscript. SS contributed to conception and design of the study, interpretation of results and substantively revised the manuscript. All authors have approved the submitted version and agreed to be accountable for their own contributions, and to ensure that any questions related to the accuracy or integrity of any part of the work, are appropriately investigated, resolved, and documented.

\section{Funding}

No external funding was obtained.

\section{Availability of data and materials}

The dataset used during the current study is available from the corresponding author on reasonable request.

\section{Ethics approval and consent to participate}

The responses collected from the participating general practitioners (GPS) were anonymous. By law, research using anonymous data are exempt from IRB approval in Norway (https://rekportalen.no/\#hjem/søke_REK). Participating GPs were informed in writing that participation was voluntary and that results could be used in research and published. Completing the survey was therefore considered implicit written consent.

\section{Consent for publication}

Not applicable.

\section{Competing interests}

The authors declare they have no competing interests.

\section{Author details}

${ }^{1}$ Norwegian Organization for Quality Improvement of Laboratory Examinations, Haraldsplass Deaconess Hospital, Bergen, Norway. ${ }^{2}$ Holter legekontor, 2034 Holter, Norway. ${ }^{3}$ Department of Clinical Science, University of Bergen, Bergen, Norway. ${ }^{4}$ Department of Thoracic Medicine, Haukeland University Hospital, Bergen, Norway. ${ }^{5}$ Department of Global Public Health and Primary Care, University of Bergen, Bergen, Norway. ${ }^{6}$ Department of Medical Biochemistry and Pharmacology, Haukeland University Hospital, Bergen, Norway.

Received: 24 August 2020 Accepted: 10 November 2020 Published online: 18 November 2020

\section{References}

1. The Norwegian Health Economics Administration (Helfo). [Måltall for refusjonsområdet lege. 2018-tall]. Norwegian Directorate of Health; 2019, available from: www.helfo.no.

2. Melbye H, Drivenes E, Dalbak LG, Leinan T, Hoegh-Henrichsen S, Ostrem A. Asthma, chronic obstructive pulmonary disease, or both? Diagnostic labeling and spirometry in primary care patients aged 40 years or more. Int J Chron Obstruct Pulmon Dis. 2011;6:597-603.

3. Rothnie KJ, Chandan JS, Goss HG, Mullerova H, Quint JK. Validity and interpretation of spirometric recordings to diagnose COPD in UK primary care. Int J Chron Obstruct Pulmon Dis. 2017;12:1663-8.

4. Sandelowsky H, Natalishvili N, Krakau I, Modin S, Stallberg B, Nager A. COPD management by Swedish general practitioners - baseline results of the PRIMAIR study. Scand J Prim Health Care. 2018;36:5-13.

5. Stavelin A, Sandberg S. Harmonization activities of Noklus - a quality improvement organization for point-of-care laboratory examinations. Clin Chem Lab Med. 2018;57:106-14.

6. Gulsvik A, Lund J, Austgard E, Høegh Henriksen S, Langhammer A, Refvem OK, et al. [Kols. Nasjonal faglig retningslinje og veileder for forebygging, diagnostisering og oppfølging]. Norwegian Directorate of Health; 2012.

7. Global Initiative for Chronic Obstructive Lung Disease (GOLD). Global strategy for the diagnosis, management, and prevention og chronic obstructive pulmonary disease (2020). 2019, Available from: https:// goldcopd.org/.

8. Norwegian Organization for Improvement of Laboratory Examinations (Noklus). Available from: www.noklus.no.

9. The R Project for Statistical Computing. Available from: www.r-project.org.

10. Hardie JA, Buist AS, Vollmer WM, Ellingsen I, Bakke PS, Morkve O. Risk of over-diagnosis of COPD in asymptomatic elderly never-smokers. Eur Respir J. 2002;20:1117-22.

11. Ho T, Cusack RP, Chaudhary N, Satia I, Kurmi OP. Under- and over-diagnosis of COPD: a global perspective. Breathe (Sheff). 2019;15:24-35.

12. Sator L, Horner A, Studnicka M, Lamprecht B, Kaiser B, McBurnie MA, et al. Overdiagnosis of COPD in subjects with unobstructed spirometry: a BOLD analysis. Chest. 2019;156:277-88.

13. Jones RC, Price D, Ryan D, Sims EJ, von Ziegenweidt J, Mascarenhas L, et al. Opportunities to diagnose chronic obstructive pulmonary disease in routine care in the UK: a retrospective study of a clinical cohort. Lancet Respir Med. 2014:2:267-76.

14. Katsimigas A, Tupper OD, Ulrik CS. Opportunistic screening for COPD in primary care: a pooled analysis of 6,710 symptomatic smokers and exsmokers. Int J Chron Obstruct Pulmon Dis. 2019;14:1633-8.

15. Sandelowsky H, Krakau I, Modin S, Stallberg B, Johansson SE, Nager A. Effectiveness of traditional lectures and case methods in Swedish general practitioners' continuing medical education about COPD: a cluster randomised controlled trial. BMJ Open. 2018;8:e021982.

16. Adams SG, Pitts J, Wynne J, Yawn BP, Diamond EJ, Lee S, et al. Effect of a primary care continuing education program on clinical practice of chronic obstructive pulmonary disease: translating theory into practice. Mayo Clin Proc. 2012;87:862-70.

17. Drexel C, Jacobson A, Hanania NA, Whitfield B, Katz J, Sullivan T. Measuring the impact of a live, case-based, multiformat, interactive continuing medical education program on improving clinician knowledge and competency in evidence-based COPD care. Int J Chron Obstruct Pulmon Dis. 2011;6:297-307.

\section{Publisher's Note}

Springer Nature remains neutral with regard to jurisdictional claims in published maps and institutional affiliations. 